\title{
エスカレータの踏段異常走行検出装置に関する研究*
}

\author{
小倉学*1, 治 田康 雅*2 \\ 吉 川 達 也*3, 庵 下 英 樹*3
}

\section{Study on Curved Rail Safety Device of Escalator}

\author{
Manabu OGURA*4, Yasumasa HARUTA, \\ Tatsuya YOSHIKAWA and Hideki ANSHITA \\ ${ }^{* 4}$ Mitsubishi Electric Corp., Human Resources Development Center, \\ 2-2-1 Akashia-Dai, Sanda-shi, Hyogo, 669-1323 Japan
}

\begin{abstract}
CRS (Curved Rail Safety Device) is one of the safety devices of the escalator. With the feature with a wide range of detection, zone type CRS is often adopted. In the zone type CRS, an operation track is generally set up along the traveling direction of the step at the upper and lower curved section of escalator. And the rise of the step due to catching shoes between step is detected as displacement of the operation track. In this type CRS, it is preferable that the operation force is constant in the whole area within the range of detection. In this paper, the conditional equation that the operation force is constant is derived. CRS with nearly constant operation force is designed, and the validity of the design is confirmed by the experiment.
\end{abstract}

Key Words: Escalators, Safety Device, Accident Prevention, Detectors, Step, Curved Rail Safety Device

\section{1. 緒言}

エスカレー夕は, 連続・大量輸送という特徵を生か し，デパート，スーパー，駅舎などを中心にわが国だ けでも 4 万台以上が稼働している。そして, 不特定多 数の市民が利用するという立場から, 安全性には十分 な配慮がなされており, 人身事故の発生頻度は極めて 低いものに抑えられている. 安全性の確保, 向上に寄 与しているものに各種の安全装置があり, 構造物が相 対運動をする箇所へ万が一手足等が食い込んだ場合， それを検知し，運転をただちに停止する機能を持つ。

このような安全装置の一つに, 踏段異常走行検出装 置(CRS：Curved Rail Safety Device)がある. CRS は, 隣接する踏段の段差が小さくなる箇所において, 踏段間へ鞉先等が食い込んだ場合，これを検出し，工 スカレータをただちに停止するための安全装置であ る. 踏段間に靴先等が食い込むと, 段差縮小動作が口 ックされるため, 上段側の踏段が浮き上がる. CRS

* 原稿受付 2006 年 8 月 7 日.

*1 正員, 三菱電機 (株) 人材開発センター(者669-1323 三田市 あかしあ台 2-2-1).

*2 正員, 三菱電機 (株) 稲沢製作所 (贾 492-8682 稲沢市菱町 1).

*3 三菱電機 (株) 稲沢製作所.

E-mail : Ogura.Manabu@ab.MitsubishiElectric.co.jp
はこの踏段の浮き上がりをリミットスイッチで検出す るもので, 踏段が段差を縮小しながら走行する領域の, ある一定範囲にわたって検出が可能なゾーンタイプ(1) と, 領域中の 1 点だけで検出するポイントタイプ(2) と に大別される.

ゾーンタイプの CRS は, 検出範囲が広いという特 徵から採用される例が多く, 踏段の浮き上がりを, 前 記一定範囲にわたって配置された作動レールの変位と して, 検出するのが一般的である。この夕、イプの CRS では, 検出範囲(踏段の進行方向)の全域にわた って, 動作力 (リミットスイッチが動作するときの作 動レールの押上げ力)が一定であることが望ましく， これまでリミットスイッチを 1 個のみ用いて, 動作力 を一定とする方法が考案されている(3). しかし，この 方法は，作動レールの両端を支持する圧縮ばねの予圧 力を零とするものであり, 作動レールを所望の位置に 保持するという, 基本的な機能を持たないものであっ た. 逆に, 予圧力が大きい場合, 作動レール両端の動 作力に比べ中央部の動作力が大きくなり，靴先等の食 い込みを確実に検出しようとした場合, 詔動作耐力が 十分に確保できないという問題が生じる.

本論文では, CRS の動作解析のための簡易モデル を作成し，その動作特性についての検討を行った。そ 
して, 動作力を一定にするための設計条件を見出し た.さらに，その条件での動作が実験においても確認 できたので，その内容について報告する.

\section{CRS の構成と動作}

$2 \cdot 1$ エスカレータの構成 図 1 は, エスカレー 夕全体と踏段部分の構成図である。エスカレー夕の各 構成要素は，トラスと呼ばれる主枠に組み付けられて いる.トラスの上部と下部に配置された上部スプロケ ット，下部スプロケット間には踏段チェーンが巻き掛 けられており，これを駆動ユニットで駆動することで， 踏段チェーンに結合された踏段が循環移動する．踏段 の両側面には，駆動ローラ(Step chain roller) と追従 ローラ(Trailing roller)が設けられており，それらを それぞれ, 駆動レール(Main track), 追従レール (Trailing track)で案内することにより，踏段の軌道 と姿勢が制御される．本論文で取上げる CRS は，踏 段の段差が変化する上下の曲部(図中 $M, N$ 部)にお いて, 追従レールに付加する形で構成されている，上 下曲部の CRS の構成, 動作には基本的な差はないた

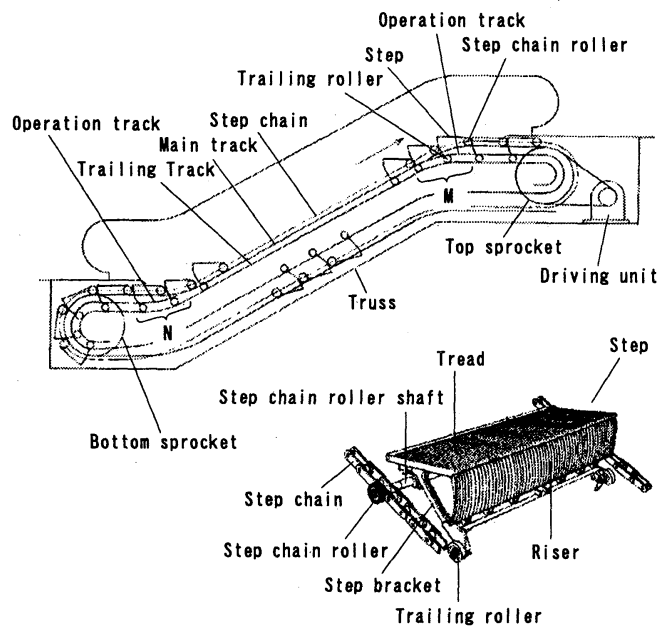

Fig. 1 Whole constitution of escalator

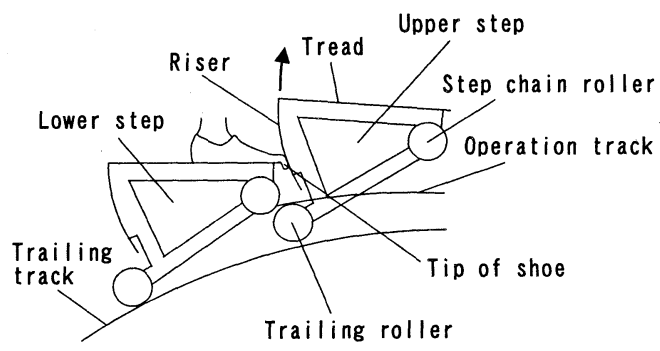

Fig. 2 Operation principle of CRS
め, 以下, 上曲部の CRS について動作原理, 詳細構成 を説明する。

$2 \cdot 2 \mathrm{CRS}$ の動作原理 図 2 は, CRS の動作原理 を示す概略図である.下段側踏段に搭乗した乗客の靴 先等が，上段側踏段のライザに押付けられた場合，曲 部で踏段間の段差が小さくなる際に，靴先が踏段間の すきまに引き込まれることがある。このとき，段差が 小さくなろうとする踏段間の相対運動がロックされる ため, 上段側踏段は駆動ローラを中心に回転運動し ライザ側が持ち上がる。これに伴い上段側踏段の追従 ローラも追従レールから離れて浮き上がる。ここで, 追従ローラの上方に作動レール(Operation track)を 配置しておくと，浮き上がった追従ローラは作動レー ルを押上げ，作動レールは変位する．このように，踏 段間への靴先等の食い込みを, 作動レールの変位とし て検出するのが, CRSの動作原理である.

$2 \cdot 3$ CRS の詳細構成図 3 は，上曲部における CRS の詳細図である. CRS の作動レールは追従レー ル上を転動する追従ローラに覆いかぶさるように，追 従レールの上方に配置されている.作動レールの両端 は，レバー A，Bにより支持されている.レバー A, $\mathrm{B}$ は，追従レールに固定されたブラケット $\mathrm{A} ， \mathrm{~B}$ に乗 る形となっており,下方へは変位できなくなってい る.一方，上方への変位に対しては，圧縮ばねのばね 力が作用するように構成されており, 締込みナットの 締込み量を変えることで, 圧縮ばねの予圧力が調整で きるようになっている，すなわち，圧縮ばねに予圧力 より大きな上方向の力が作用しない限り, 作動レール

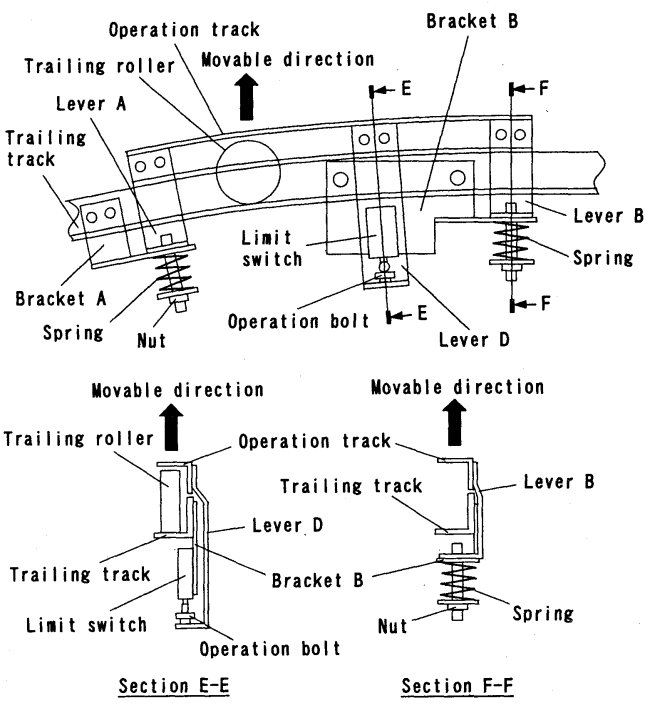

Fig. 3 Detail constitution of CRS 
は持ち上がらない.また，作動レールの中間部分には， レバーDが取付けられており，作動レールのレバーD 取付位置が上方へ一定量変位した際, ブラケットBに 固定されたリミットスイッチが押し込まれて，スイッ チが動作し, エスカレータが停止するよう構成されて いる.

2・4 CRS の理想的な動作力 CRS は，靴先等が 踏段間に食い込んだときには確実に動作しなければな らないが，ライザへのベビーカーの押付けやスーツケ 一スキャリヤによる踏段の引つ掛け, 蹴飛ばし等のい たずらに対しては，動作してほしくない.したがって， 動作力，すなわち，リミットスイッチが押し込まれる ときの, 追従ローラが作動レールを押上げる力の設定 が重要となる.

図 4 は, 追従ローラが作動レールを押上げる位置を 横軸にとり, 理想的な動作力と圧縮ばねの予圧力が大 きい場合の動作力を，模式的に比較したものである. 理想的な動作力は領域 $\mathrm{A}$ (ベビーカーの押付けやいた ずらによる作動レールの押上げ力）よ大きく，領域 $\mathrm{B}$ (鞉先等の食い込みによる作動レールの押上げ力)よ り小さい範囲にあり，できるだけ一定となっているこ とが望まれる。これに対し, 圧縮ばねの予圧力が大き い場合には，作動レール両端での動作力に比べ，中央 の動作力が大きい山形の特性となり, 靴先等の食い込 み時に確実に動作(動作力が領域 B にかからない)さ せようとすると, 両端の動作力が領域 A に入り込ん でしまい, ベビーカーの押付けやいたずらに対し CRS が反応するという, 誤動作耐力が十分でない状 態となる.この誤動作耐力を向上させるためには, CRS の設計パラメータである圧縮ばねのばね定数, 予圧力, リミットスイッチの位置, 動作ストローク等 をうまく設定することにより，動作力が作動レールの 全範囲にわたって領域 A と領域 B の間にあり，しか

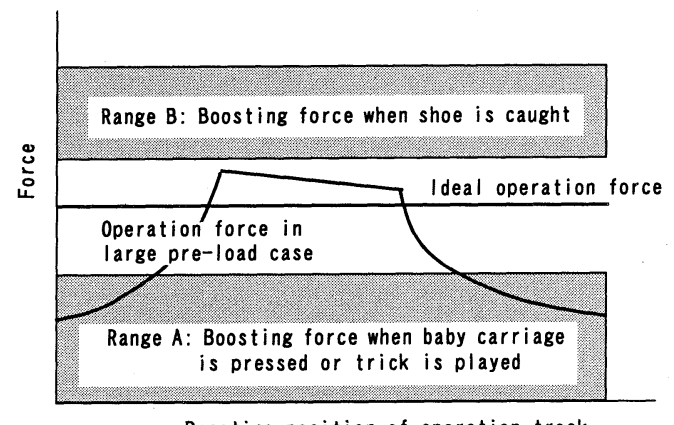

Boosting position of operation track

Fig. 4 Comparison of ideal operation force with existing
もできるだけ一定となるようにする必要がある。

3 章では，上記パラメータスタディを行うために作 成した CRS の簡易モデルと, 動作力一定となる条件 について説明する。

\section{CRS のモデル化と動作カ一定の条件}

図 5 にCRS の簡易モデルを示す。作動レールをま つすぐな剛体ばりとし，その両端 $\mathrm{A}, \mathrm{B}$ を予圧力 $P_{A}$, $P_{B}$ のかけられたばね定数 $k_{A}, a \times k_{A}$ の圧縮ばねで支 持されているとしている。ここで， $a$ は正の定数であ る.作動レールの全長を $l$ とし, A 端から距離 $p \times$ $l(0 \leqq p \leqq 1)$ の位置 D に, 作動レールの変位を検出す るリミットスイッチが配置され, A 端から距離 $b \times$ $l(0 \leqq b \leqq 1)$ の位置 Cで作動レールが追従ローラによ り押上げられるとする。

初期状態 $\mathrm{AB}$ であった作動レールの点 $\mathrm{C}$ に, 押上げ 力 $F_{C}$ が作用したとする. $F_{C}$ の端点 $\mathrm{A}, \mathrm{B}$ における 分力 $F_{A}, F_{B}$ がそれぞれ, 予圧力 $P_{A}, P_{B}$ よりも大きい 場合, 点 $\mathrm{A}, \mathrm{B}$ は持ち上がる. しかし, 分力が予圧力 $P_{A}, P_{B}$ よりも小さい場合は，持ち上がらない.した がって, 作動レールの動作を考える場合, 分力 $F_{A}, F_{B}$ と予圧力 $P_{A}, P_{B}$ との大小関係で, 場合分けして考元 る必要がある.ここで, 分力 $F_{A}, F_{B}$ は,

$$
\begin{aligned}
& F_{A}=(1-b) F_{C} \\
& F_{B}=b F_{C} \cdots \cdots \cdots
\end{aligned}
$$

である、そして, 場合分けの境界となる条件は， $F_{A}=$ $P_{A}, F_{B}=P_{B}$ より,

$$
\begin{aligned}
& F_{C}=\frac{1}{1-b} P_{A} . \\
& F_{C}=\frac{1}{b} P_{B} \cdots .
\end{aligned}
$$

である. 式 ( 3 ) は点 $\mathrm{A}$ が持ち上がり始めるときの $F_{C}$ の值, 式 (4) は点 B が持ち上がり始めるときの $F_{C}$ の 值を表す。また, 点 $\mathrm{C} に F_{C}=F$ の力が加わったとき，

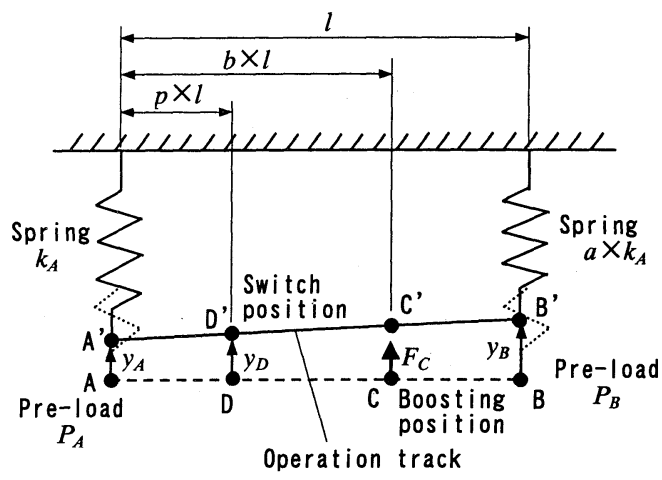

Fig. 5 Simple model of CRS 
点 $\mathrm{A}, \mathrm{B}$ の少なくとも一方が持ち上がって, 点 $\mathrm{D}$ の変 位が $y_{D}=y_{x}$ になり, リミットスイッチが動作したと すると,この $y_{x}$ が動作ストロークであり,$F$ が動作

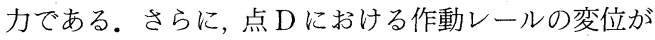
$y_{x}$ であるときの, 点 $\mathrm{A}, \mathrm{B}$ の変位を $y_{1}, y_{2}$ として, 以 下場合分けをして動作力 $F$ とば放定数 $k_{A}$, 予圧力 $P_{A}, P_{B}$, 動作ストローク $y_{x}$, 定数 $a, p$, 変数 $b$ の関 係を検討する。ただし，現実性を考えて，

$$
F \geqq 0, \quad P_{A} \geqq 0, \quad P_{B} \geqq 0, \quad y_{x} \geqq 0
$$

とする。

（1） $F_{A}<P_{A}$ かつ $F_{B}<P_{B}$ の場合

作動レールが動作することはないため, 動作力に関 する関係式はなし。

（2） $F_{A} \geqq P_{A}$ かつ $F_{B}<P_{B}$ の場合

この場合, 点 $\mathrm{A}$ は持ち上がり, 点 $\mathrm{B}$ は持ち上がら ない. $F_{A}=F_{1}$ のときリミットスイッチが動作したと すると式(1)より，

$$
y_{1}=\frac{F_{1}-P_{A}}{k_{A}}=\frac{(1-b) F-P_{A}}{k_{A}}
$$

また,

$$
y_{2}=0
$$

よって,

$$
y_{x}=(1-p) y_{1}
$$

式(6)より,

$$
y_{x}=(1-p) \frac{(1-b) F-P_{A}}{k_{A}}
$$

であるから，動作力 $F$ は，

$$
F=\frac{1}{1-b}\left(\frac{k_{A} y_{x}}{1-p}+P_{A}\right)
$$

となる，さらに，この式を書き換えると，

$$
F=\frac{F_{1}}{1-b}
$$

となる.式(11) は，点 $\mathrm{A}$ を持ち上げたときの動作力 が決められている場合, $F_{A} \geqq P_{A}$ かつ $F_{B}<P_{B}$ となる 条件下での動作力が, 押上げ位置のみの関数となるこ とを意味しており，実際の動作と符合する。また，動 作力が式(10)，(11)で与学られる $b$ の範囲は,

$$
0 \leq b<\frac{(1-p) P_{B}}{k_{A} y_{x}+(1-p)\left(P_{A}+P_{B}\right)}
$$

である。

（3） $F_{A}<P_{A}$ かつ $F_{B} \geqq P_{B}$ の場合

この場合は, 点 $\mathrm{A}$ は持ち上がらず, 点 $\mathrm{B}$ は持ち上 がる. $F_{B}=F_{2}$ のときリミットスイッチが動作したと すると, $y_{1}, y_{2}$ は,

$$
\begin{aligned}
& y_{1}=0 \\
& y_{2}=\frac{F_{2}-P_{B}}{a k_{A}}=\frac{b F-P_{B}}{a k_{A}}
\end{aligned}
$$

であり, $y_{x}$ は,

$$
y_{x}=p y_{2}=p\left(\frac{b F-P_{B}}{a k_{A}}\right) \cdots
$$

となる.よって，

$$
F=\frac{1}{b}\left(\frac{a k_{A} y_{x}}{p}+P_{B}\right)
$$

でありこの式を書き換えて，

$$
F=\frac{F_{2}}{b}
$$

が得られる. 動作力が式(16)，(17)で与えられる $b$ の 範囲は,

$$
\frac{a k_{A} y_{x}+p P_{B}}{a k_{A} y_{x}+p\left(P_{A}+P_{B}\right)}<b<1
$$

である。

（4） $F_{A} \geqq P_{A}$ かつ $F_{B} \geqq P_{B}$ の場合

この場合, 点 $\mathrm{A}, \mathrm{B} へ$ へ分力が両方とも予圧力より 大きいため, 両点とも持ち上がる.したがって, 作動 レールに関する力とモーメントの釣合いから，

$$
\begin{aligned}
& k_{A} y_{1}+P_{A}+a k_{A} y_{2}+P_{B}=F \\
& \left(k_{A} y_{1}+P_{A}\right) l=(1-b) l F
\end{aligned}
$$

という関係が成り立ち，これらの式から $y_{1}, y_{2}$ を求め ると,

$$
\begin{aligned}
& y_{1}=\frac{(1-b) F-P_{A}}{k_{A}} \\
& y_{2}=\frac{b F-P_{B}}{a k_{A}} \ldots \ldots . . .
\end{aligned}
$$

であり, 動作ストローク $y_{x}$ は，

$$
y_{x}=y_{1}+p\left(y_{2}-y_{1}\right)
$$

であるから, 式(21)〜(23) から動作力 $F$ は，

$$
F=\frac{a k_{A} y_{x}+a(1-p) P_{A}+p P_{B}}{a(1-p)+b(a p-a+p)}
$$

となる.ここで, 分母の $b$ にかかるカッコ内が 0 , す なわち,

$$
\begin{gathered}
a p-a+p=0 \\
\therefore a=\frac{p}{1-p}
\end{gathered}
$$

の関係が成り立つとき, 式(24)は,

$$
F=\frac{a k_{A} y_{x}+p\left(P_{A}+P_{B}\right)}{p}
$$

となる。よって，押上げ位置 $b$ によらず動作力一定の CRS が実現できる．ただし，式(24)，(26)から動作力 を求められる $b$ の範囲は,

$$
\frac{(1-p) P_{B}}{k_{A} y_{x}+(1-p)\left(P_{A}+P_{B}\right)} \leq b \leq \frac{a k_{A} y_{x}+p P_{B}}{a k_{A} y_{x}+p\left(P_{A}+P_{B}\right)}
$$

である. 参考文献 ( 3 )の CRS は $p=0.5, a=1$ で, し かも予圧力 $P_{A}=P_{B}=0$ の特殊な場合のみを取扱った ものである.

4 章では, 以上の計算式を基に, 両端での動作力 $F_{1}$, 
$F_{2}$ が固定されているときの動作力について, パラメ ータスタディを行い, 動作力特性について考察する.

\section{4. 両端の動作力を固定した場合の 動作力特性の考察}

CRS の動作力設定を行う際, 両端の動作力を所望 の值に合わせるという手法は，よく用いられる。ここ では, 両端の動作力を固定し， A 端，B端のばねのば ね定数の比 $a$ と動作ストローク $y_{x}$ を, それぞれ変化 させたときの動作力の変化についてシミュレーション 検討し, 結果の考察を行う.

$4 \cdot 1 \quad a$ の違いによる動作力の変化 表 1 に検討 に用いた計算条件を示す，ただし，力の大きさはすべ て，踏段間へ靴先が食い込んだときの押上げ力の下限 值 $F_{m}$ で割って, 無次元化している. 図 6 は, 表 1 の 条件下で $a$ をパラメータとして計算した, 動作力特性 である. $a=1.326$ のケースは, $a$ と $p$ の関係が式 (25) を満たしている. 両端に㧈ける動作力 $F_{1}, F_{2}$ を 固定した場合, 式(12)の領域の動作力は式(11)で表さ れ，式(18)の領域の動作力は式(17)で表される。その 間の領域の動作力は式(24) から求められる。また，そ れぞれの領域の境界は式 (4) と式(11)で表される曲線 の交点, および式 ( 3 ) と式(17)で表される曲線の交点 として, 求められる.すなわち,

Table 1 Calculative condition when $a$ is changed

\begin{tabular}{|c|c|}
\hline$p$ & 0.57 \\
\hline$y_{x}(\mathrm{~mm})$ & 2.5 \\
\hline$F_{1}$ & 0.53 \\
\hline$F_{2}$ & 0.53 \\
\hline$k_{A}(/ \mathrm{mm})$ & 0.05 \\
\hline
\end{tabular}

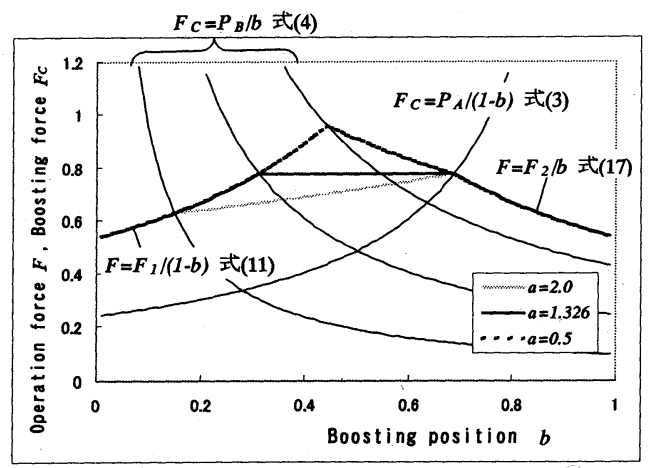

Fig. 6 Operation force characteristic when $a$ is changed

$$
b=\frac{P_{B}}{F_{1}+P_{B}}
$$

および,

$$
b=\frac{F_{2}}{F_{2}+P_{A}^{\prime}}
$$

である.ここで， $F_{1} ， F_{2}$ をさらに分解して考えると，

$$
\begin{aligned}
& F_{1}=P_{A}+k_{A} y_{1} \\
& F_{2}=P_{B}+a k_{A} y_{2}
\end{aligned}
$$

であり, 式(30)には $a$ が含まれていないが, 式(31)に は含まれている。すなわち, $F_{1}, F_{2}$ が固定の場合, $a$ が変化すると $P_{A}$ は変化しないが, $P_{B}$ は変化する. $a$ の変化に伴い, 式 ( 3 )で表される曲線は移動しないが, 式(4)で表される曲線は移動し, 式(11)で表される曲 線との交点も移動する.

さらに図 6 からも明らかなように, $a$ を変化させる ことで動作力の最大值を小さくすること(あるいは， 最小值を大きくすること)には限界があり, その值は 式 ( 3 ) と (17) の交点, よって $b$ が式(29) から求められ る値であるときの $F$ の值となり，

$$
F=F_{2}+P_{A}
$$

この式は, 最大動作力が B 端の設定動作力よりも, 最 低でも $\mathrm{A}$ 端のばねにかけた予圧力 $P_{A}$ の分だけ, 大き くなることを示している.

$4 \cdot 2 y_{x}$ の違いによる動作力の変化 表 2 は, シ ミュレーションに用いた計算条件である。ここでのシ ミュレーションは, $a$ と pの関係が式(25)を満足する

Table 2 Calculative condition when $y_{x}$ is changed

\begin{tabular}{|l|c|}
\hline$p$ & 0.57 \\
\hline$a$ & 1.326 \\
\hline$F_{1}$ & 0.53 \\
\hline$F_{2}$ & 0.5 \\
\hline$k_{A}(/ \mathrm{mm})$ & 0.073 \\
\hline
\end{tabular}

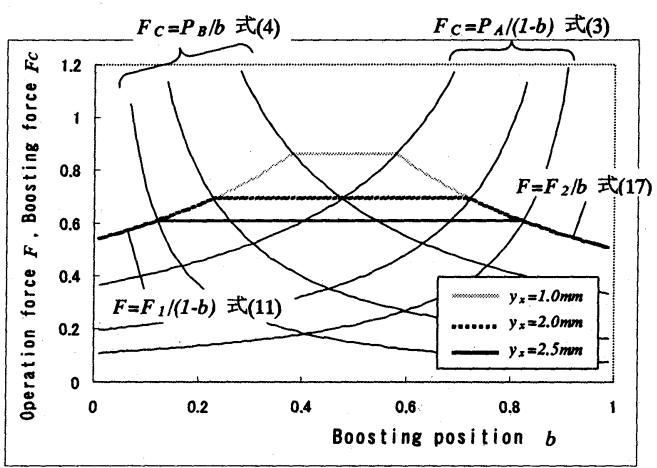

Fig. 7 Operation force characteristic when $y_{x}$ is changed 
場合について行った。図 7 は, 表 2 の条件下で $y_{x}$ を パラメータとして計算した動作力特性である. $4 \cdot 1$ 項 の場合と同様に, 式(12)の範囲の動作力は式(11)で表 され，式(18)の領域の動作力は式(17)で表される。 そ して, これらの範囲の動作力は $y_{x}$ の変化の影響は受 けず, 同一曲線上に乗る。一方, $F_{1}, F_{2}$ の内訳は式 (30)，(31)であり， $y_{x}$ が変化すると $y_{1}, y_{2}$ が変化する から， $F_{1}, F_{2}$ が固定であっても $P_{A}, P_{B}$ は両方とも変 化する.よって, 式 (3)，（4)で表される曲線は $y_{x}$ の変化とともに移動し, 式(11),（17)で表される曲線 との交点も移動する，したがって，式(27)の範囲の動 作力は変化し, 今回のケースでは, $y_{x}$ が大きくなるほ ぞ動作力が小さくなる傾向にある.また, $y_{x}$ が変化 しても, 式(27)の範囲では動作力が一定に保たれてお り, $y_{x}=2.5 \mathrm{~mm}$ のケースでは, 作動レールの広い範 囲にわたって，動作力が一定に保たれていることがわ かる.

\section{5. 実験による確認}

4 章では, シミュレーションにより CRS の動作力 特性の検討を行った。特に，作動レールの全範囲にわ たって動作力をほぼ一定に保てる，CRS の実現可能 性を示した。そこで, 本章では, 現行の CRS と最適

Table 3 Specification of existing CRS

\begin{tabular}{|c|c|}
\hline$p$ & 0.57 \\
\hline$a$ & 1.0 \\
\hline$y_{x}(\mathrm{~mm})$ & 2.5 \\
\hline$F_{1}$ & 0.53 \\
\hline$F_{2}$ & 0.5 \\
\hline$P_{A}$ & 0.33 \\
\hline$P_{B}$ & 0.35 \\
\hline$k_{A}(/ \mathrm{mm})$ & 0.033 \\
\hline
\end{tabular}

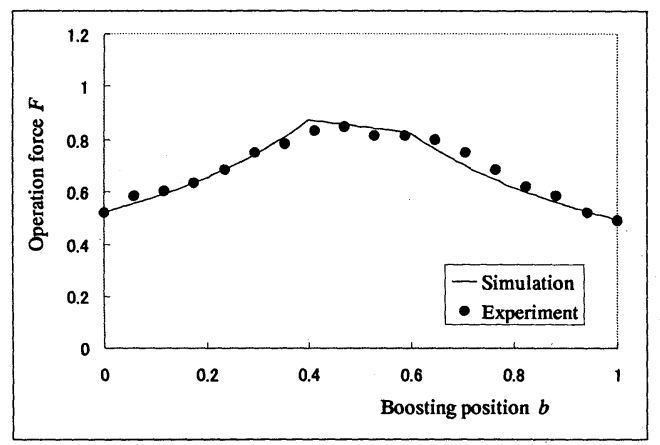

Fig. 8 Operation force characteristic of existing CRS
と考えられるCRSの動作力について，シミュレーシ ヨンと実験の比較を行い, モデル化やシミュレーショ ンの妥当性を検証する.

表 3 に現行 CRS の仕様, 図 8 にその動作力特性を 示し, 表 4 に最適化した CRSの仕様, 図 9 にその動 作力特性を示す. 最適化計算を行う条件としては, (1) 動作力の最大值 $\leqq 0.76 F_{m}$, (2) 動作力の最小値 $=0.67$ $F_{m}$, (3)pおよび $y_{x}$ の值は従来と同じ, (4) $a$ とpは式 (25) の関係とする, (5)予圧力 $\geqq 0.085 F_{m}$, (6) 予圧力負 荷時のばねの縮み $\geqq 0.6 \mathrm{~mm}$ の 6 条件を用いた. 現行 CRS，最適化したCRSのいずれにおいても，シミュ レーション結果と実験結果はよく一致しており，モデ ル化およびシミュレーションの妥当性が確認された。 現行 CRS の動作力の最大値と最小值の差に比べ, 最 適化した CRS の最大值と最小值の差は $1 / 3$ 程度にな っており，作動レールの全範囲にわたって動作力をほ ぼ一定にできている。 また，最大值が抑えられ，最小 值が引上げられていることから, 裕度が大きく, 誤動 作耐力も向上した CRS が得られていることがわか る.なお, 作動レールの両端部分を完全に動作力一定 としていないのは，作動レールを保持するために，あ る程度の予圧力が必要 (上記最適化の条件(5)，(6) とな るためである.

Table 4 Specification of optimal CRS

\begin{tabular}{|c|c|}
\hline$p$ & 0.57 \\
\hline$a$ & 1.326 \\
\hline$y_{x}(\mathrm{~mm})$ & 2.5 \\
\hline$F_{1}$ & 0.67 \\
\hline$F_{2}$ & 0.67 \\
\hline$P_{A}$ & 0.085 \\
\hline$P_{B}$ & 0.085 \\
\hline$k_{A}(/ \mathrm{mm})$ & 0.1 \\
\hline
\end{tabular}

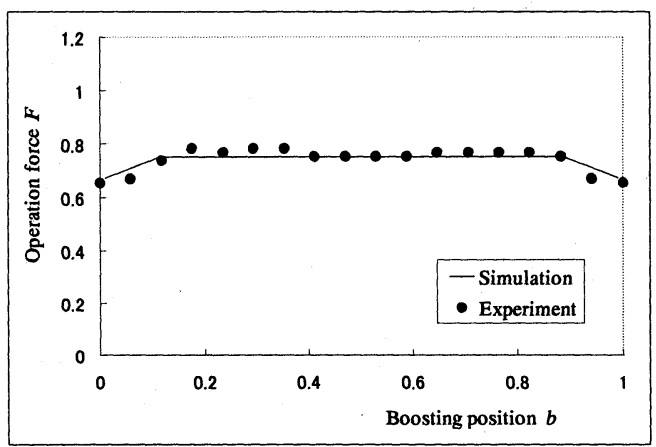

Fig. 9 Operation force characteristic of optimal CRS 


\section{6. 結 言}

CRS の動作解析のための簡易モデルを作成し，そ の動作特性についての検討を行った。その結果, 以下 の結論を得た。

（1）作動レールの押上げ位置によらず, 動作力が 一定となる設計条件が明らかとなった。

（2）CRS 動作力特性のシミュレーション結果と 実験結果がよく一致し，モデル化およびシミュレーシ ヨンの妥当性が確認できた。

（3）シミュレーションによる動作力特性のパラメ
ータスタディ結果を基に, CRS の最適設計を行い, 裕 度が大きく, 誤動作耐力も向上した CRS の提案を行 った.

\section{文献}

(1) Syoji, H. et al., Operation track for escalator, Published utility model application, JP, 54-136286, U (1979).

(2) Nakazawa, T. et al., Safety device for escalator, Published patent application, JP, 54-003790, A (1979).

(3) Nakamura, H. et al., Safety device for escalator, Examined utility model application publication, JP, 63046456, Y (1988). 